\title{
A Characterization for the Deformation Behavior of As-Cast P91 Alloy Steel and Utilization in Hot Extrusion Process
}

\author{
Lu Jia, ${ }^{1,2}$ Yongtang Li, ${ }^{1,2}$ and Yang Zhang ${ }^{3}$ \\ ${ }^{1}$ Materials Science and Engineering Department, Taiyuan University of Science and Technology, Taiyuan, Shanxi 030024, China \\ ${ }^{2}$ Shanxi Key Laboratory of Metallic Materials Forming Theory and Technology, Taiyuan University of Science and Technology, \\ Taiyuan, Shanxi 030024, China \\ ${ }^{3}$ Hebei Hongrun Nuclear Equipment Science and Technology Co., LTD, Hebei 061300, China
}

Correspondence should be addressed to Yongtang Li; liyongtang@tyust.edu.cn

Received 24 February 2017; Revised 24 May 2017; Accepted 1 June 2017; Published 13 July 2017

Academic Editor: Michele Zappalorto

Copyright (C) $2017 \mathrm{Lu}$ Jia et al. This is an open access article distributed under the Creative Commons Attribution License, which permits unrestricted use, distribution, and reproduction in any medium, provided the original work is properly cited.

\begin{abstract}
The constitutive models of as-cast P91 alloy steel were investigated by unidirectional thermal compression tests, which were conducted over a wide range of temperature and strain rate on Gleeble-3500 thermal simulation machine. The constitutive models were coupled with finite element method to simulate the hot extrusion process. Furthermore, the industrial hot extrusion experiment on actual pipe was conducted on $500 \mathrm{MN}$ vertical extrusion machine and the load-displacement data during the extrusion were recorded. Comparisons between the numerical simulation and industrial experimental results were carried out and confirmed that the developed constitutive models can be used in the simulation and industrial research of compact hot extrusion process.
\end{abstract}

\section{Introduction}

Heavy caliber thick-wall pipes are widely used in the fields such as large supercritical thermal power, nuclear power, and petrochemical engineering. The current production process of heavy caliber thick-wall pipe is the punching and hot extrusion (PHE) process shown in Figure 1. This PHE process has several defects including long production cycle, serious waste in material, and investments of large scale equipment. In order to solve these disadvantages, a new compact hot extrusion (CHE) process shown in Figure 2 was proposed by $\mathrm{Li}$ et al. [1]. During the CHE process, the as-cast billet is demolding under hot extrusion temperature and directly extruded on the extrusion machine. The short forming process realizes the integration on shape forming and performance improving. Thus, the hot deformation behaviors of as-cast billet during CHE process are required to be further investigated.

P91 martensite alloy steel (10Cr9MolVNb) is one of the leading materials of heavy caliber thick-wall pipe due to its high thermal conductivity, high coefficient of linear expansion, corrosion-resistant ability, and moderate price [2-6].
Investigations and great progress on the behaviors of asforged P91 alloy steel have been done based on the experimental research and simulation results [7-11]. However, the reports of hot deformation performance on as-cast P91 alloy steel have not been seen yet.

The object of this study is to establish an innovative constitutive model which can accurately be applied to the simulation and experimental research on the CHE process. The hot deformation behaviors of as-cast P91 alloy steel were investigated by hot compression tests. In addition, the constitutive models of as-cast P91 alloy steel were coupled with the finite element analysis of hot extrusion on heavy caliber thick-wall pipe. The comparisons between the simulation and the industrial hot extrusion experiment were then discussed with the load-displacement data.

\section{Experimental}

2.1. Materials and Methods. The chemical composition of as-cast P91 alloy steel was (wt.\%) $0.084 \mathrm{C}-0.28 \mathrm{Mn}-0.38 \mathrm{P}$ $-0.005 \mathrm{~S}-0.28 \mathrm{Si}-8.63 \mathrm{Cr}-0.96 \mathrm{Mo}-0.209 \mathrm{~V}-0.084 \mathrm{Nb}-0.21 \mathrm{Ni}$ $-0.031 \mathrm{~N}$-(bal) Fe. The hot compression tests were carried out 


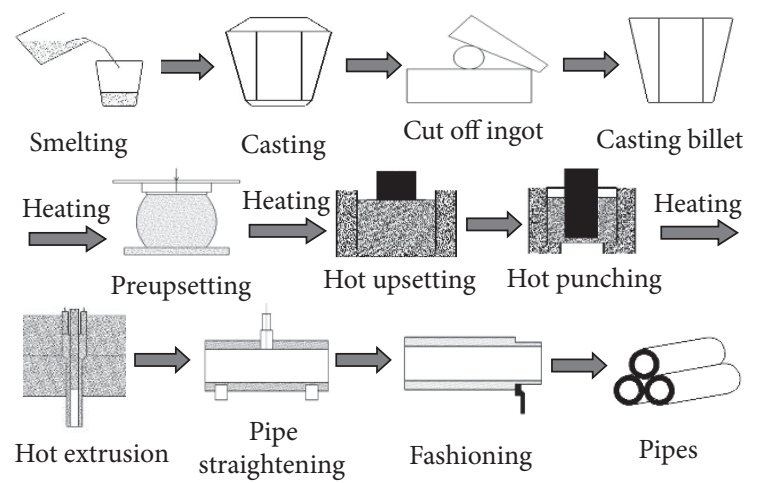

FIgURE 1: The punching and hot extrusion process.

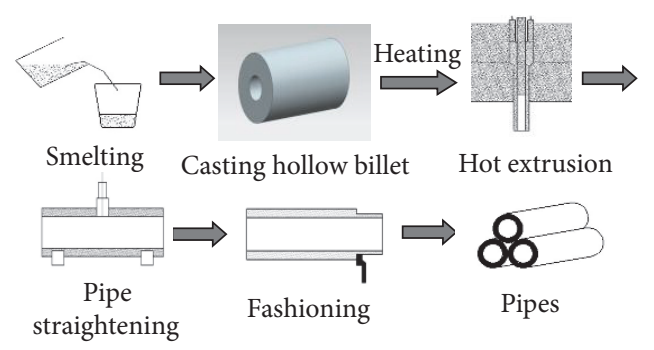

FIgURE 2: The compact hot extrusion process.

on a Gleeble-3500 thermomechanical simulator. Cylindrical specimens were machined with $8 \mathrm{~mm}$ in diameter and $12 \mathrm{~mm}$ in height.

The specimens were deformed at the reduction of $60 \%$ in height. Different deformation temperatures (from 1173 to $1473 \mathrm{~K}$ ) and different strain rates (from 0.01 to $5 \mathrm{~s}^{-1}$ ) were used in the hot compression tests. The specimens were firstly preheated to $1473 \mathrm{~K}$ at a rate of $5 \mathrm{~K} / \mathrm{s}$ and held for $5 \mathrm{~min}$ at isothermal conditions for fully austenitizing. Then the specimens were cooling to the deformation temperature at the rate of $5 \mathrm{~K} / \mathrm{s}$ and held for $30 \mathrm{~s}$ for the homogenization of temperature and compressed at the selected conditions. Finally, the compressed specimens were rapidly quenched in water.

2.2. Experimental Results and Analysis. The true strain-stress curves of as-cast P91 alloy steel under different deformation conditions are depicted in Figure 3. It can be obtained that the flow stress curves are sensitively dependent on the strain rate and the temperature. It increases with the increase of strain rate and decreases with the increase of temperature. The dynamic recrystallization (DRX) occurs under higher temperature and lower strain rate.

During the hot deformation process, the flow stress is sensitive to the work hardening and the dynamic softening [10]. At the beginning of the deformation, the flow stress increases with the increasing strain. The material is under an unstable status due to the increasing dislocation density. The stored energy turns into a driving force for the dislocation migration. When the strain reaches to the critical strain, the dynamic recovery occurs and the flow stress increases owing to the confliction between softening and hardening. Moreover, with the strain continuing to increase, the work hardening and softening reach to a certain balance and the flow stress reaches to a plateau as well. Thus, the critical strain and work hardening are the significant parameters for the flow stress and should be considered in the constitutive models.

\section{Constitutive Model for As-Cast P91 Alloy Steel}

The experimental true stress-strain curves were fitted with the logarithmic from Hollomon equation $\left(\sigma=s \cdot \varepsilon^{p}\right)$, where $\sigma$ is the flow stress, $s$ is the strength coefficient, $\varepsilon$ is the plastic strain, and $p$ is the work hardening exponent. The work hardening rate $\theta(d \sigma / d \varepsilon)$ in this investigation can be expressed from the experimental researches as $[12,13]$

$$
\theta_{i}=\frac{d \sigma}{d \varepsilon}=\frac{\sigma_{i+1}-\sigma_{i-1}}{\varepsilon_{i+1}-\varepsilon_{i-1}}=l \sigma+k,
$$

where $l$ is a parameter which effected by the deformation temperature and strain rate and $k$ is a constant. The relationships between work hardening rate and flow stress can be shown in Figure 4 (the deformation temperature was $1473 \mathrm{~K}$ ), $\sigma_{c}$ is the critical stress, $\sigma_{p}$ is the peak stress, and $\sigma_{s}$ is the saturation stress.

It can be obtained in Figure 4, by extending the imaginary line with $X$-axis, and the intersection (where $\theta=0, \sigma=\sigma_{s}$ ) was gotten. From (1), constant $k$ can be found as $k=-l \sigma_{s}$. In Figure 4, the flow stress has a linear relationship between work hardening rate and flow stress before critical stress, and $l$ is the slope of the line, so the point of critical strain and stress is the inflection point of the curves. From (1), the flow stress can be expressed as

$$
\sigma=\exp (l \cdot \varepsilon) \cdot C-\frac{k}{l}
$$

With the condition of $\sigma=\sigma_{c}$ and $\varepsilon=\varepsilon_{c}$, the constant $C$ can be described as

$$
C=\frac{\sigma_{c}-\sigma_{s}}{\exp \left(l \varepsilon_{c}\right)} .
$$

Substituting (3) into (2) the constitutive model of flow stress can be obtained as

$$
\sigma=\exp \left[l \cdot\left(\varepsilon-\varepsilon_{c}\right)\right]\left(\sigma_{c}-\sigma_{s}\right)+\sigma_{s} .
$$

The parameters in this model will be established and determined in the following parts. The values of $\sigma_{c}, \sigma_{p}$, and $\sigma_{s}$ under different deformation conditions can be obtained and illustrated in Table 1.

3.1. Calculations of the Activation Energy and $Z$ Parameter. Arrhenius equations were represented [14] which are used in describing the relationship by hyperbolic sine, and it can be expressed with the Zener-Hollomom $(Z)$ parameter as follows:

$$
Z=\dot{\varepsilon} \exp \left(\frac{Q}{R T}\right)=A[\sinh (\alpha \sigma)]^{n}
$$




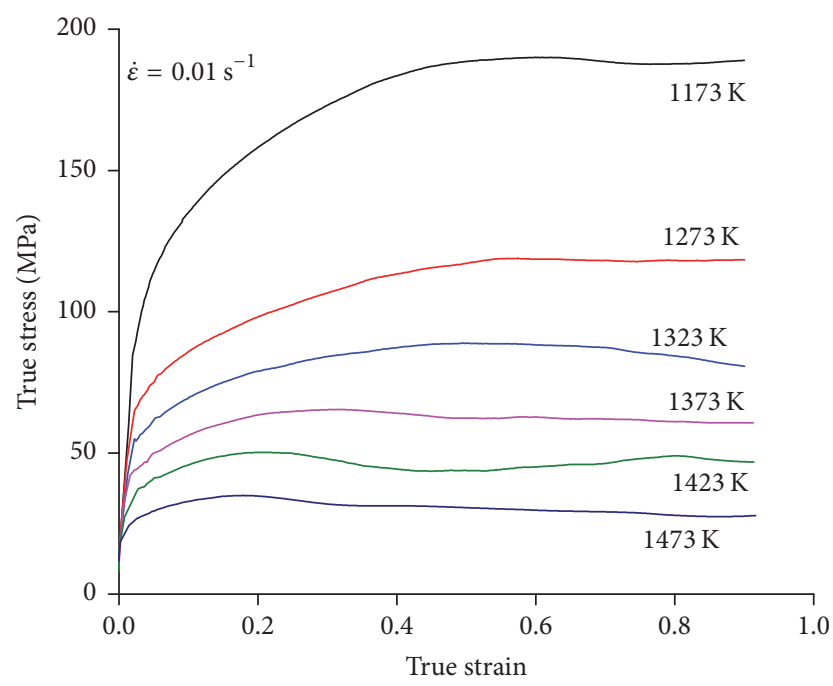

(a)

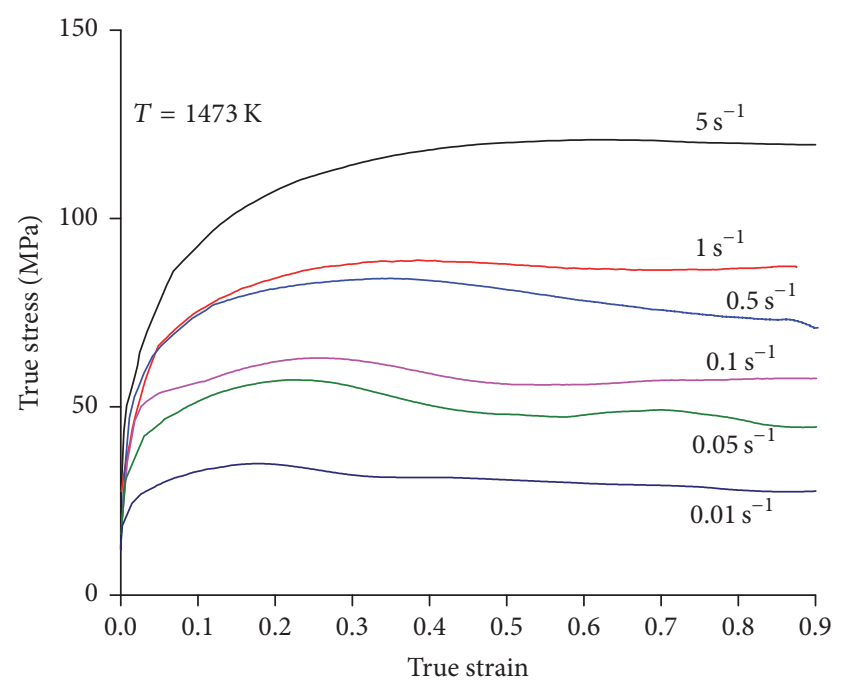

(b)

Figure 3: The true stress-strain curves of different deformation temperatures at strain rate of $0.1 \mathrm{~s}^{-1}$ (a); different strain rates at deformation temperature of $1473 \mathrm{~K}$ (b).

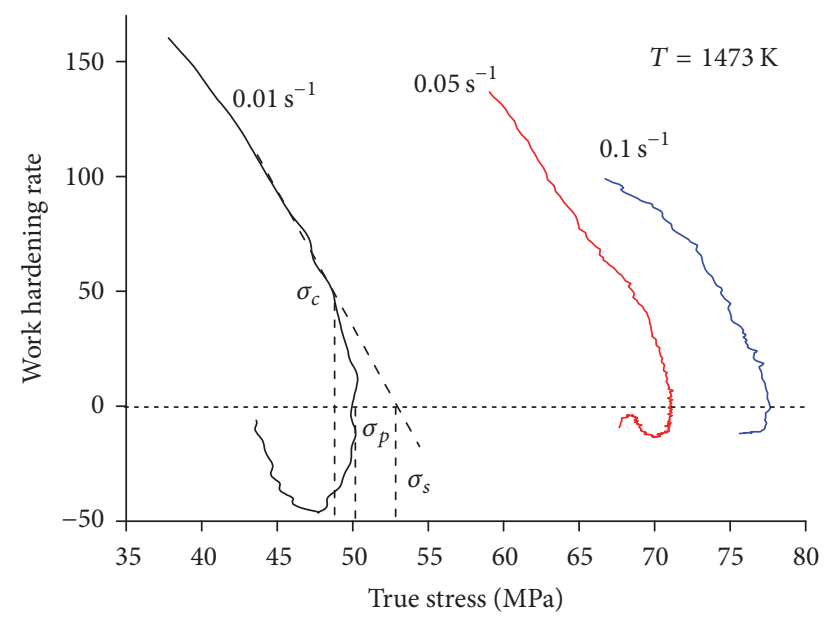

FIGURE 4: The relationships between work hardening rate and flow stress.

where $Q$ is the activation energy $(\mathrm{kJ} / \mathrm{mol}), R$ is the constant $\left(8.314 \mathrm{~J} \cdot \mathrm{mol}^{-1} \cdot \mathrm{K}^{-1}\right), T$ is deformation temperature $(\mathrm{K})$, and $A$ and $\alpha$ are material constants. According to (5), the strain rate can be expressed as

$$
\dot{\varepsilon}=A \cdot F(\sigma) \exp \left[-\frac{Q}{R T}\right]
$$

where $F(\sigma)$ is the function of the stress which can be described in different conditions [15]; the functional relations between flow stress and strain rate can be described as follows:

$$
\begin{aligned}
& F(\sigma)=\sigma^{n_{1}} \quad(\alpha \sigma<0.8) \\
& F(\sigma)=\exp (\beta \sigma) \quad(\alpha \sigma<1.2),
\end{aligned}
$$

TABLE 1: The values of $\sigma_{c}, \varepsilon_{c}, \sigma_{p}$, and $\sigma_{s}$ under different deformation conditions.

\begin{tabular}{lccccc}
\hline Strain rate $\left(\mathrm{s}^{-1}\right)$ & $\begin{array}{c}T \\
(\mathrm{~K})\end{array}$ & $\begin{array}{c}\sigma_{c} \\
(\mathrm{MPa})\end{array}$ & $\varepsilon_{c}$ & $\begin{array}{c}\sigma_{p} \\
(\mathrm{MPa})\end{array}$ & $\begin{array}{c}\sigma_{s} \\
(\mathrm{MPa})\end{array}$ \\
\hline \multirow{3}{*}{0.01} & 1473 & 34.65 & 0.15 & 34.87 & 41.30 \\
& 1423 & 49.35 & 0.16 & 50.14 & 55.01 \\
& 1373 & 64.63 & 0.22 & 65.33 & 68.57 \\
& 1323 & 88.2 & 0.37 & 88.79 & 104.84 \\
\hline \multirow{3}{*}{0.05} & 1473 & 57.01 & 0.21 & 57.13 & 65.23 \\
& 1423 & 70.2 & 0.25 & 71.10 & 76.54 \\
& 1373 & 85.45 & 0.30 & 86.80 & 92.87 \\
\multirow{3}{*}{0.1} & 1323 & 114.14 & 0.34 & 115.15 & 127.31 \\
\hline \multirow{2}{*}{0.5} & 1473 & 62.44 & 0.22 & 62.97 & 78.30 \\
& 1423 & 76.01 & 0.26 & 77.38 & 81.74 \\
& 1373 & 96.05 & 0.31 & 96.70 & 107.84 \\
\hline \multirow{2}{*}{1} & 1473 & 83.28 & 0.27 & 84.07 & 98.14 \\
& 1423 & 89.05 & 0.37 & 90.45 & 113.35 \\
\hline
\end{tabular}

where $\beta$ and $n_{1}$ are the materials dependent constants. Substituting the value of $\sigma_{p}$ into (5) (7) and taking natural logarithm of (7), the relationships between $\ln \dot{\varepsilon}$ and $\ln \sigma, \ln \dot{\varepsilon}$ and $\sigma$ are illustrated in Figures 5 and 6, respectively. $n_{1}\left(n_{1}=\right.$ $8.78215)$ and $\beta(\beta=0.06965)$ are determined from the slopes of straight line in Figures 5 and 6 , where $\alpha, \beta$, and $n_{1}$ are related by $\alpha=\beta / n_{1}$, and $\alpha$ can be obtained as 0.00793 .

Taking natural logarithm of (6), activation energy $Q$ can be expressed as

$$
Q=R n\left\{\frac{\partial[\ln \sinh (\alpha \sigma)]}{\partial(1 / T)}\right\} .
$$




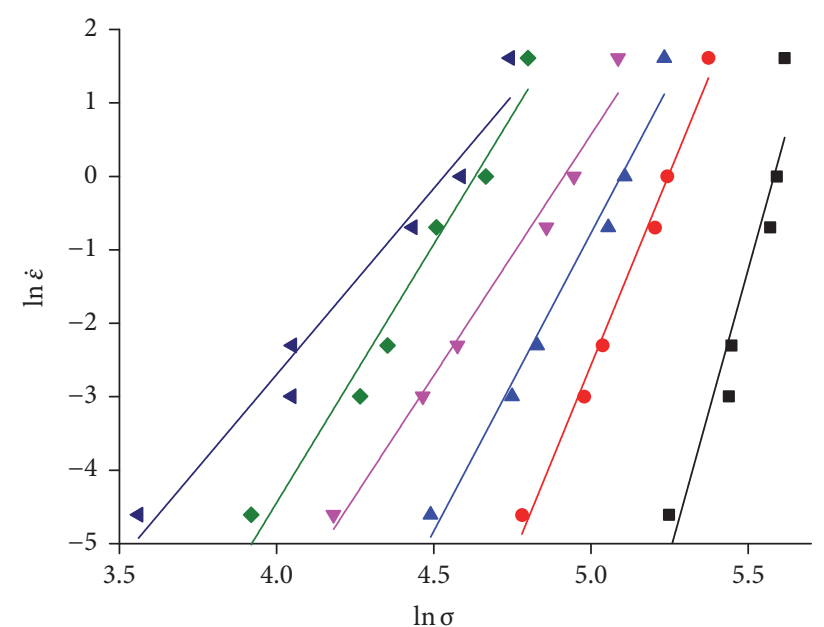

Temperature

$\begin{array}{ll}\text { - } 1173 \mathrm{~K} & \nabla 1373 \mathrm{~K} \\ \text { - } 1273 \mathrm{~K} & \diamond 1423 \mathrm{~K} \\ \text { \ } 1323 \mathrm{~K} & \checkmark 1473 \mathrm{~K}\end{array}$

FIgURE 5: Relationship between $\ln \sigma$ and $\ln \dot{\varepsilon}$.

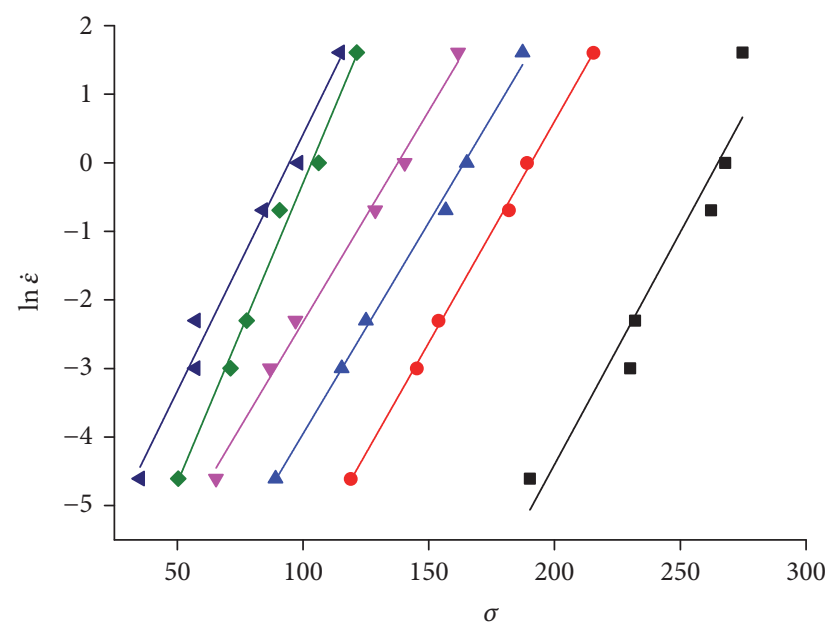

Temperature

$\begin{array}{ll}\text { - } 1173 \mathrm{~K} & \nabla 1373 \mathrm{~K} \\ \text { - } 1273 \mathrm{~K} & \forall 1423 \mathrm{~K}\end{array}$

$\checkmark 1323 \mathrm{~K} \quad 41473 \mathrm{~K}$

FIGURE 6: Relationship between $\sigma$ and $\ln \dot{\varepsilon}$.

Similarly, taking natural logarithm on both sides of (5), the relationship between $\ln \sinh (\alpha \sigma)$ and $\ln \dot{\varepsilon}$ can be obtained. Using the linear plot of $\ln \sinh (\alpha \sigma)$ versus $\ln \dot{\varepsilon}$ (Figure 7), the value of $n$ can be calculated $(n=6.2154)$. The value of $Q$ can be obtained by using the same method (in Figure 8 , the linear fit between $\ln \sinh (\alpha \sigma)$ and $1000 / T)$; the average value of $Q$ is $328.1 \mathrm{~kJ} / \mathrm{mol}$.

3.2. Calculation of Parameter l. According to (4), the flow stress can be expressed as

$$
\ln \left(\frac{\sigma-\sigma_{s}}{\sigma_{c}-\sigma_{s}}\right)=l \cdot\left(\varepsilon-\varepsilon_{c}\right) .
$$

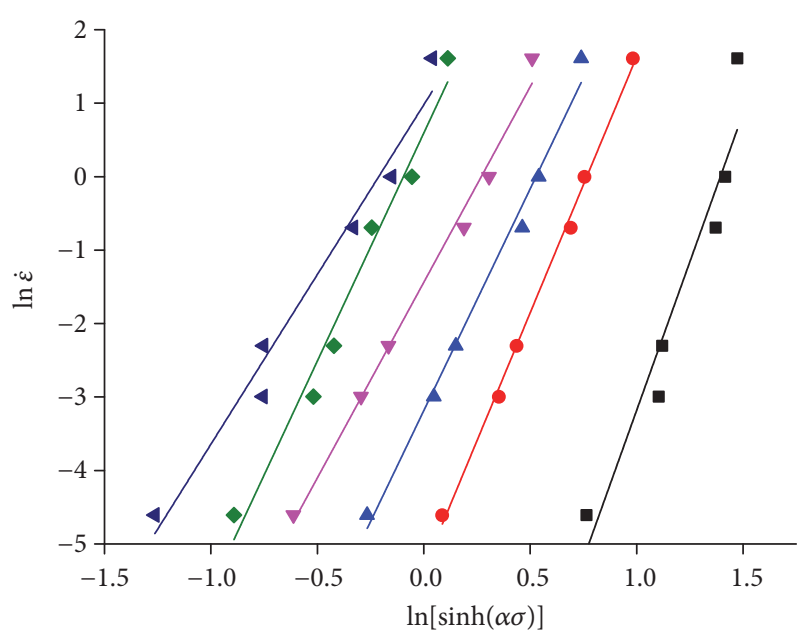

Temperature

$\begin{array}{ll}\text { - } 1173 \mathrm{~K} & \nabla 1373 \mathrm{~K} \\ \text { - } 1273 \mathrm{~K} & \checkmark 1423 \mathrm{~K} \\ \text { \ } 1323 \mathrm{~K} & \triangleleft 1473 \mathrm{~K}\end{array}$

FIgURE 7: Relationship between $\ln \dot{\varepsilon}$ and $\ln [\sinh (\alpha \sigma)]$.

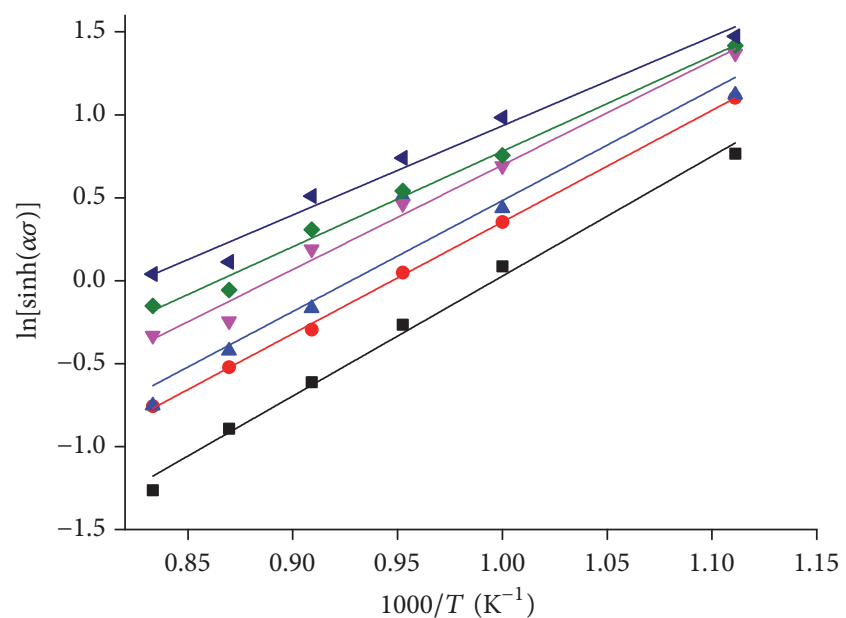

FIGURE 8: Relationship between $1000 / T$ and $\ln [\sinh (\alpha \sigma)]$.

The determination of parameter $l$ can be obtained from (9). The linear plot of $\ln \left[\left(\sigma-\sigma_{s}\right) /\left(\sigma_{c}-\sigma_{s}\right)\right]$ versus $\left(\varepsilon-\varepsilon_{c}\right)$ can be seen in Figure 9, and $l$ is determined as the slopes of the lines. As mentioned above, $l$ is sensitive to strain rate and deformation temperature which is similar with parameter $Z$. So establish a relationship between $Z$ and $l$ as

$$
l=a \cdot \exp (b Z)+c
$$

where $a, b$, and $c$ are the material parameters. The values of $Z$ can be obtained in (6), and plotting $Z$ and $l$ in Figure 10 . There has an exponential relationship between $Z$ and $l$ in Figure 10. Using the nonlinear regression in (10), all the 


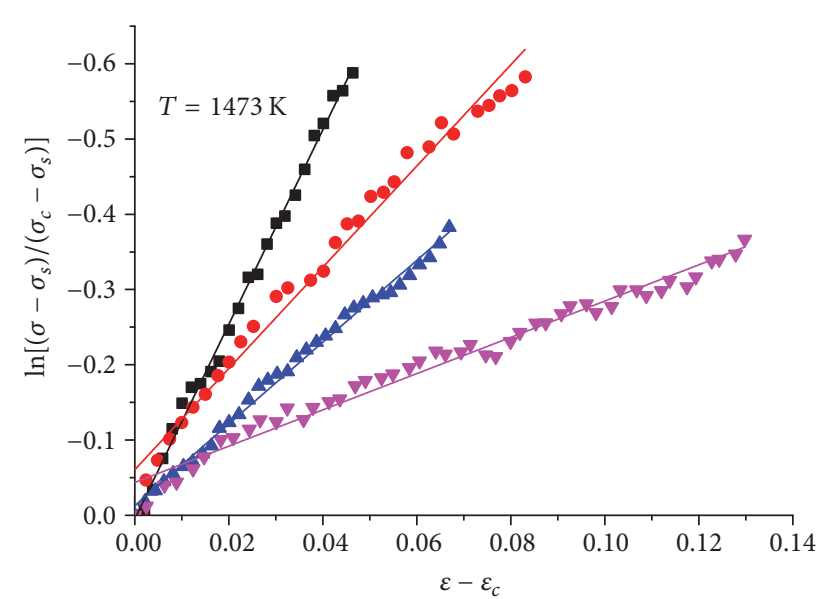

Strain rate

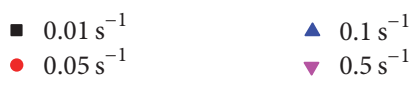

(a)

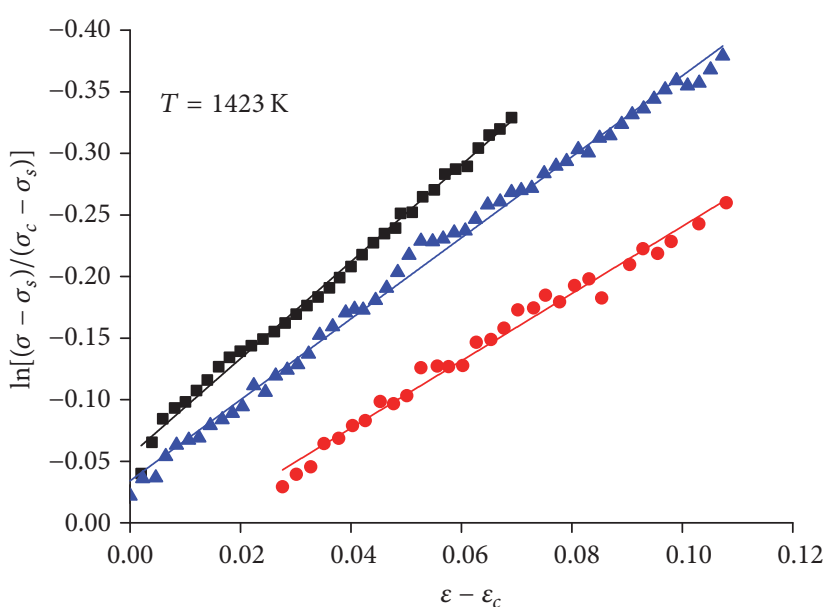

Strain rate

$$
\text { - } 0.01 \mathrm{~s}^{-1} \quad \boldsymbol{\Delta} 0.1 \mathrm{~s}^{-1}
$$$$
\text { - } 0.05 \mathrm{~s}^{-1}
$$

(b)

FIGURE 9: Relationship between $\left(\varepsilon-\varepsilon_{c}\right)$ and $\ln \left[\left(\sigma-\sigma_{s}\right) /\left(\sigma_{c}-\sigma_{s}\right)\right]$ at $1473 \mathrm{~K}(\mathrm{a}) ; 1423 \mathrm{~K}(\mathrm{~b})$.

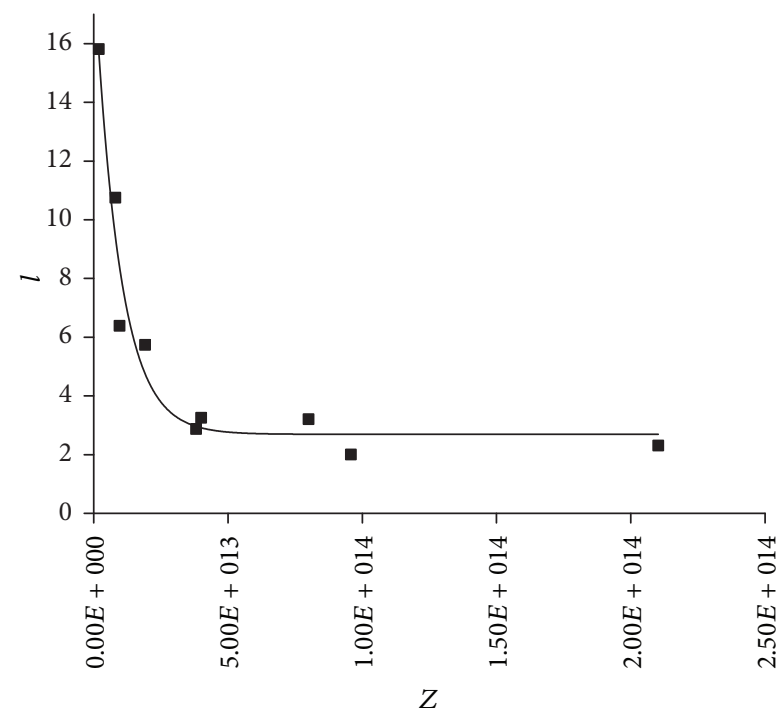

FIGURE 10: Relationship between $l$ and $Z$.

three parameters can be obtained. Parameters $a, b$, and $c$ are calculated to be $16.019,-0.107$, and 2.692 , respectively. Thus, (10) becomes

$$
l=16.019 \cdot \exp (-0.107 Z)+2.692 .
$$

3.3. Calculations of $\varepsilon_{c}$ and $\sigma_{c}$. The critical stress $\sigma_{c}$ and critical strain $\varepsilon_{c}$ cannot be directly obtained from the experiment data. Kim et al. [16-18] established the relationships between $\varepsilon_{c}, \sigma_{c}$, and $Z$ under hot deformation, and it can be expressed as

$$
\begin{aligned}
\varepsilon_{c} & =a_{1} \ln Z+b_{1} \\
\sigma_{c} & =a_{2} \ln Z+b_{2} .
\end{aligned}
$$

The values of $a_{1}, b_{1}, a_{2}$, and $b_{2}$ can be obtained by using linear regression as shown in Figure 11. The values of $a_{1}, b_{1}, a_{2}$, and $b_{2}$ are $0.035,-1.03,10.55$, and -312.61 , respectively. Hence, the critical strain and stress can be represented as

$$
\begin{aligned}
\varepsilon_{c} & =0.035 \ln Z-1.03 \\
\sigma_{c} & =10.55 \ln Z-312.61 .
\end{aligned}
$$

3.4. Calculation of $\sigma_{s}$. Saturated stress $\sigma_{s}$ cannot be directly obtained from the strain-stress curves as critical stress. It can be obtained according to Figure 4. From (5), the mathematical model of saturated stress is shown in (14):

$$
Z=A_{2}\left[\sinh \left(\alpha \sigma_{s}\right)\right]^{n_{2}} .
$$

Taking the nature logarithm on both sides of (14) gives

$$
\ln Z=\ln A_{2}+n_{2} \ln \left[\sinh \left(\alpha \sigma_{s}\right)\right] .
$$

The relationship of $\sigma_{s}$ and $Z$ can be expressed as

$$
\sigma_{s}=\frac{1}{\alpha}\left[\sinh ^{-1}\left(\frac{Z}{A_{2}}\right)^{1 / n_{2}}\right] .
$$

The value of constants $n_{2}$ and $A_{2}$ can be obtained using linear regression as presented in Figure 12. In summary, the model for $\sigma_{s}$ can be represented as follows

$$
\sigma_{s}=126.103 \cdot \sinh ^{-1}\left(5.63 \times 10^{-16} Z\right)^{6.25} \text {. }
$$




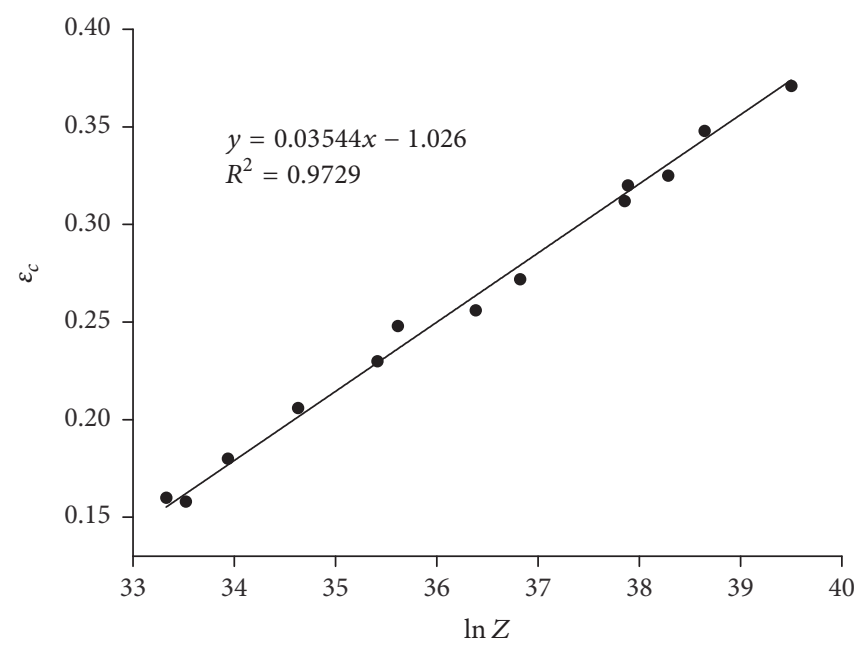

(a)

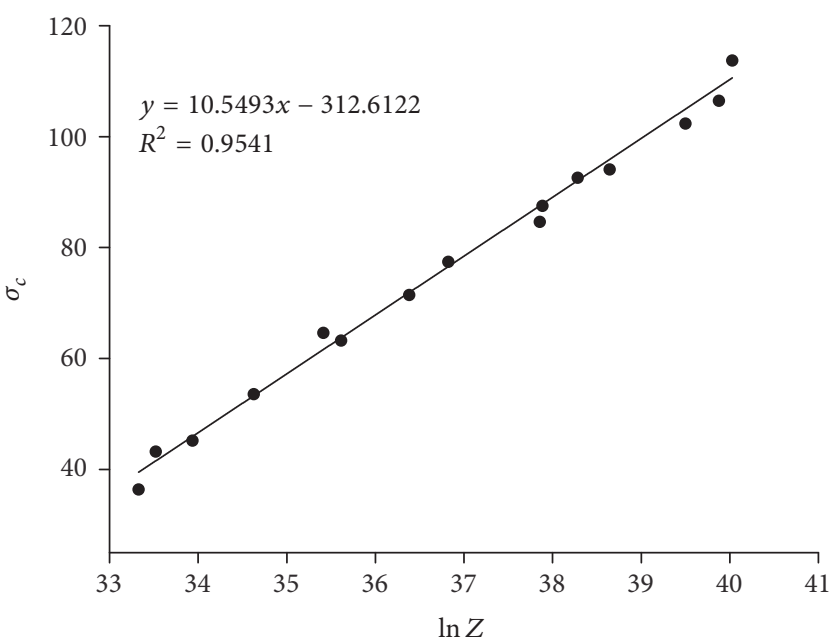

(b)

FIGURE 11: The relationships between $\varepsilon_{c}$ and $\ln Z$ (a); $\sigma_{c}$ and $\ln Z$ (b).

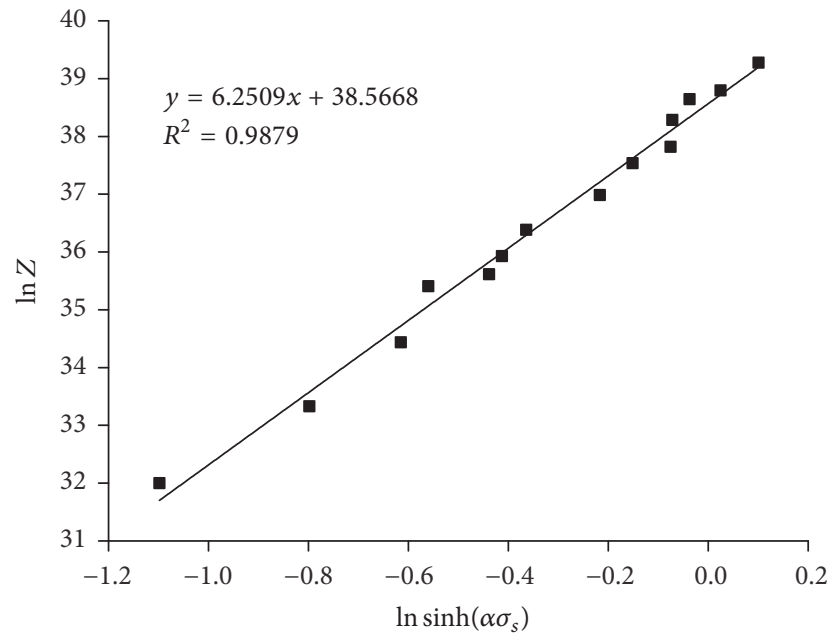

FIGURE 12: Relationship between $\ln Z$ and $\ln \left[\sinh \left(\alpha \sigma_{s}\right)\right]$.

3.5. Verification of the Proposed Constitutive Model. The mathematical model for predicting flow stress of as-cast P91 alloy steel during the hot deformation can be summarized as

$$
\begin{aligned}
\sigma & =\exp \left[l \cdot\left(\varepsilon-\varepsilon_{c}\right)\right]\left(\sigma_{c}-\sigma_{s}\right)+\sigma_{s} \\
l & =16.019 \cdot \exp (-0.107 Z)+2.692 \\
\varepsilon_{c} & =0.035 \ln Z-1.03 \\
\sigma_{c} & =10.55 \ln Z-312.61 \\
\sigma_{s} & =126.103 \cdot \sinh ^{-1}\left(5.63 \times 10^{-16} Z\right)^{6.25} \\
Z & =\dot{\varepsilon} \exp \left(\frac{328100}{R T}\right) .
\end{aligned}
$$

Figure 13 shows the comparisons of the experimental and predicted flow stress by the proposed constitutive model.
TABLE 2: The correlation coefficients under different deformation conditions.

\begin{tabular}{lcccccc}
\hline \multirow{2}{*}{$T(\mathrm{~K})$} & \multicolumn{7}{c}{ Strain rate $\left(\mathrm{s}^{-1}\right)$} \\
& 0.01 & 0.05 & 0.1 & 0.5 & 1 & 5 \\
\hline 1173 & 0.813 & 0.865 & 0.981 & 0.946 & 0.815 & 0.823 \\
1273 & 0.836 & 0.872 & 0.869 & 0.968 & 0.965 & 0.857 \\
1323 & 0.865 & 0.886 & 0.846 & 0.864 & 0.945 & 0.978 \\
1370 & 0.908 & 0.928 & 0.947 & 0.885 & 0.907 & 0.958 \\
1423 & 0.904 & 0.921 & 0.927 & 0.912 & 0.934 & 0.879 \\
1473 & 0.876 & 0.875 & 0.978 & 0.897 & 0.982 & 0.887 \\
\hline
\end{tabular}

It is undeniable that there have deviations between the experimental data and the calculations of the value fitting. So taking the correlation coefficient $R$ to study the accuracy of the calculated data, $R$ can be obtained by the following equation:

$$
R=\frac{\sum_{i=1}^{i=N}\left(\sigma_{\exp }^{i}-\bar{\sigma}_{\exp }\right)\left(\sigma_{P}^{i}-\bar{\sigma}_{P}\right)}{\sqrt{\sum_{i=1}^{i=N}\left(\sigma_{\exp }^{i}-\bar{\sigma}_{\exp }\right)^{2} \sum_{i=1}^{i=N}\left(\sigma_{P}^{i}-\bar{\sigma}_{P}\right)^{2}}}
$$

where $\sigma_{\exp }^{i}$ is the experimental data, $\sigma_{P}^{i}$ is the predicted data, $\bar{\sigma}_{\exp }$ is the experimental average data, and $\bar{\sigma}_{P}$ is the average predicted data. The correlation coefficient $R$ under different deformation conditions is illustrated in Table 2. The smaller the distinctness between $R$ and 1, the lesser the error of the constitutive model. From Table 2, the result indicated that the proposed model can give an accurate and precise estimate of flow stress for as-cast P91 alloy steel.

\section{Utilization in the Research on the Hot Extrusion of CHE Process}

The hot extrusion is a process with the characteristics of high strain rate and large deformation degree, and the deformation 

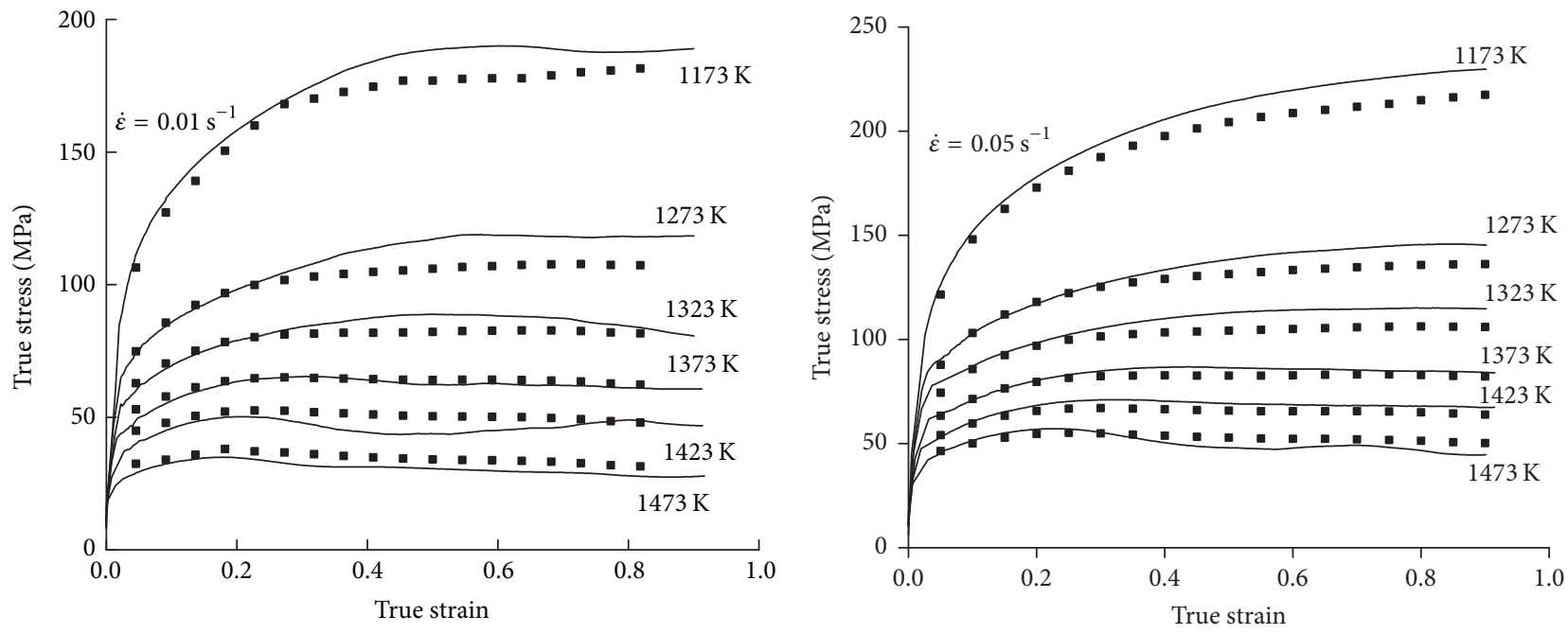

- Experiment
Predicted

(a)

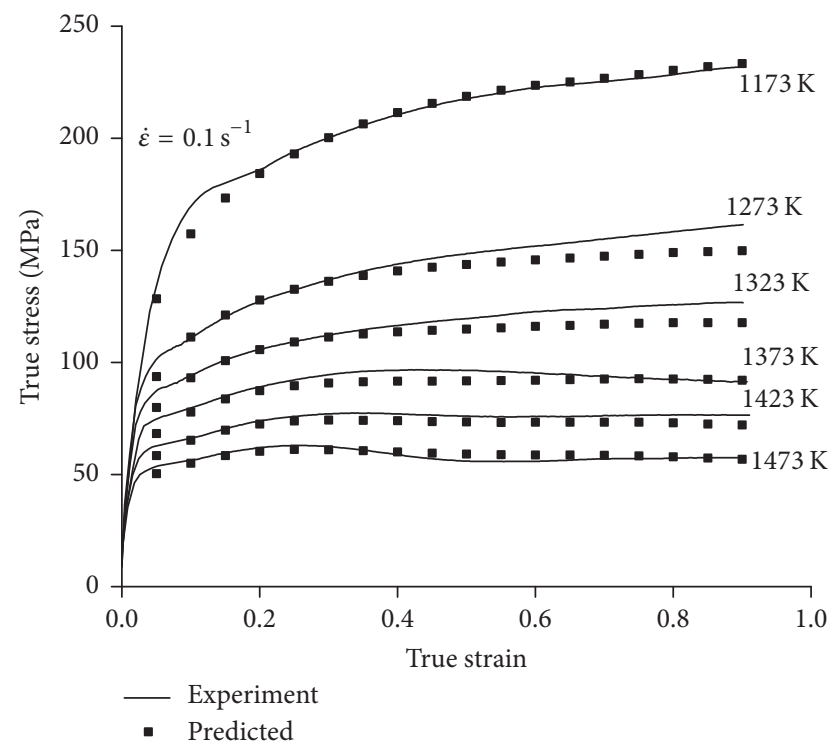

(c)

- Experiment

(b)

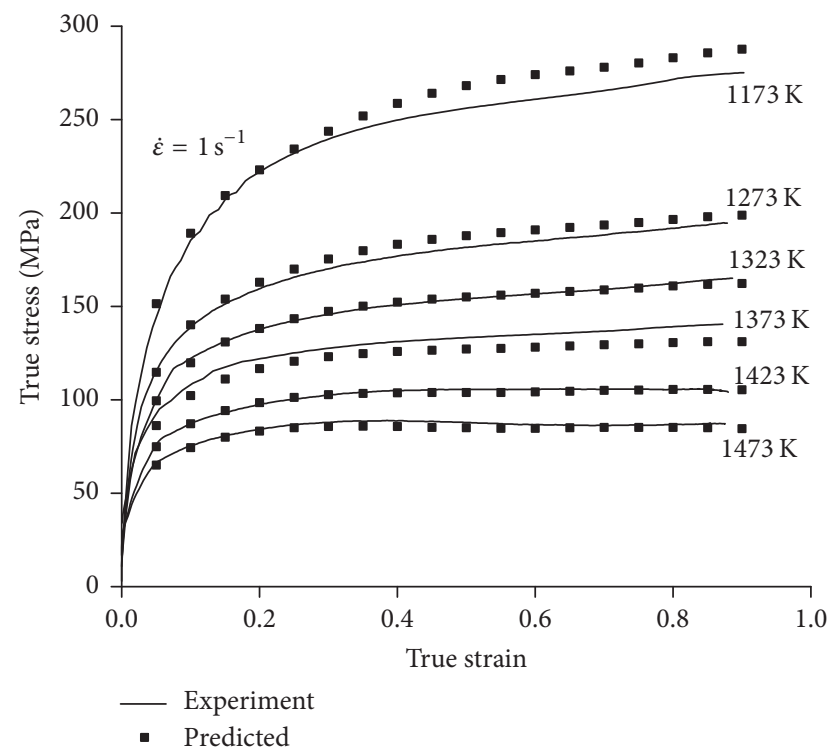

(d)

FIGURE 13: Comparisons between predicted and experiment flow stress by the proposed constitutive model under different deformation temperatures at strain rate of $0.01 \mathrm{~s}^{-1}(\mathrm{a}) ; 0.05 \mathrm{~s}^{-1}(\mathrm{~b}) ; 0.1 \mathrm{~s}^{-1}(\mathrm{c}) ; 1 \mathrm{~s}^{-1}$ (d).

conditions are more complicated than the hot compression tests. It is vital to study the flow stress during the hot extrusion process. Thus, the application of the as-cast P91 alloy steel constitutive model on the CHE hot extrusion process should be further studied and explored. The finite element (FE) method is the efficient and economical alternative method for studying the flow stress behavior during hot deformation [19-21]. Hence, the constitutive model of the as-cast p91 alloy steel was encoded into the DEFORM platform by the FORTRAN language. The hot extrusion numerical simulation results were compared with the industrial experimental research.
4.1. The Thermal-Mechanical FE Model. According to the geometric symmetry of the billet and extrusion pipe, the 3D axisymmetric simplified FE models were established in Figure 14. The thermal-mechanical FE model combined with the constitutive model of as-cast P91 alloy steel was encoded into DEFORM platform. During the simulation, the ascast billet moves with the movement of terrace die while the die and needle keep static. The material of the billet was as-cast P91 steel, and the die was H-13 die steel. The required simulation conditions for the reliability evaluation of the thermal-mechanical coupled FE model are shown in Table 3. 
TABLE 3: Hot extrusion parameters setting for the thermalmechanical coupled FE model.

\begin{tabular}{lc}
\hline Parameter & Content \\
\hline Billet size $(\mathrm{mm})$ & $\phi 1253 \times$ \\
& $\phi 500 \times 1000$ \\
Initial billet temperature $(\mathrm{K})$ & 1533 \\
Initial die temperature $(\mathrm{K})$ & 573 \\
Extrusion ratio & 9 \\
Extrusion speed $(\mathrm{mm} / \mathrm{s})$ & 50 \\
Die taper angle $\left(^{\circ}\right)$ & 42 \\
Coulomb friction coefficient & 0.04 \\
Thermal emissivity of blank & 0.7 \\
$\begin{array}{l}\text { Environment temperature }(\mathrm{K}) \\
\text { Heat convection coefficient between billet and } \\
\text { extrusion tolls }\left(\mathrm{W} \cdot \mathrm{m}^{-2} \cdot \mathrm{K}^{-1}\right)\end{array}$ & 293 \\
$\begin{array}{l}\text { Heat convection coefficient between billet and air } \\
\left(\mathrm{W} \cdot \mathrm{m}^{-2} \cdot \mathrm{K}^{-1}\right)\end{array}$ & 1100 \\
\end{tabular}

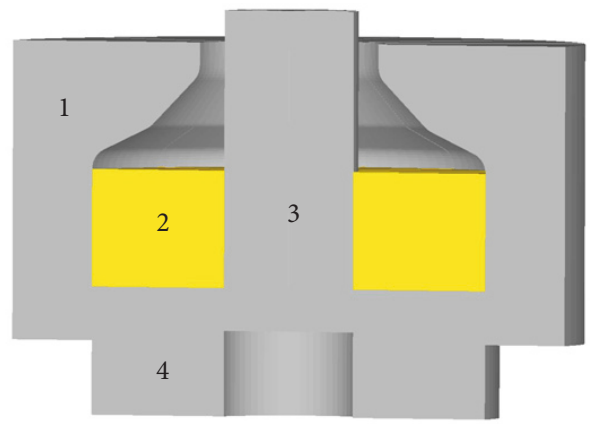

FIgURE 14: The geometric model of the hot extrusion process. 1: die; 2: as-cast billet; 3 : extrusion needle; 4 : terrace die.

\subsection{Industrial Hot Extrusion Experiment on Heavy Caliber} Thick-Wall Pipe. The hot extrusion experiment was carried out by the $500 \mathrm{MN}$ vertical hot extrusion equipment (Figure 15) in the factory. The hot extrusion process was investigated by using the same extrusion parameters (Table 3) as FE analysis. The billet was presprayed with glass lubricant. The $80 \mathrm{~mm}$ in height glass lubrication gasket was placed between the billet and the terrace die. During the extrusion process, the load-displacement data of the terrace die were measured.

4.3. The Comparisons between FE Analysis and Hot Extrusion Experiment. Figure 16(a) shows the experimental billet; Figure $16(\mathrm{~b})$ is the simulated initial temperature distribution of the billet. It can be seen that the billet temperature decreases due to the heat convection and heat emissivity. The temperature of the surfaces is lower than the inner. Figure 17 shows the extrusion production pipe of this experiment, and the dimensional accuracy of the pipe meets the requirements of the industrial.

The distributions of temperature field, effective strain, and stress during the hot extrusion process are illustrated in Figure 18. It can be found that the heat is generated during the extrusion process, and the temperature increases in the large deformation area (the conical surface and the die orifice). The temperature increases due to the transfer of the plastic deformation heat and the dynamic friction heat. The effective strain and stress field during the hot extrusion process indicated that the extrusion force increased during the process. When the material flows out of the die orifice, the effective strain remains stable while the effective stress reaches to the peak value. Furthermore, it also can be seen in Figure 18(c) that the values of the effective stress are larger than zero; this illustrates that the stress state during the hot extrusion is the compressive stresses rather than the tensile stresses. It shows that the hot cracking will not appear on the extruded pipe which is verified by the industrial experiment shown in Figure 17.

The comparisons of the load-displacement curves between the measured and simulated results are illustrated in Figure 19. The results showed that the maximum load value of the experiment is $430 \mathrm{MN}$, while the simulation value is $410 \mathrm{MN}$. The difference was due to the simplification of the FE analysis; the actual industrial extrusion conditions are more complicated. Thus the error is in a reasonable deviation range. The computed results present a good estimate of the relationship between load and displacement during the hot extrusion.

The simulation and experimental results indicated that the proposed constitutive model of as-cast P91 alloy steel can give an accurate and precise estimate of the flow stress and it can be used to the analyze of the CHE process. In other words, the constitutive models established from the compressive tests can be applied to the industrial research and simulation.

\section{Conclusions}

The deformation characteristics of as-cast P91 alloy steel were investigated by means of the unidirectional hot compression experiments over a practical range of temperatures and strain rates. According to the results, the flow stress is sensitive to the work hardening and the critical strain. A parameter $l$ was proposed to express the constitutive models. The thermal-mechanical finite element model was further developed by encoding the constitutive models into DEFORM platform. According to the actual thick-wall pipe, the hot extrusion process was simulated and experimented, respectively. Comparisons between the simulated and experimental results were carried out and confirmed that the developed constitutive models can be used in the industrial and simulation research of compact hot extrusion process. 


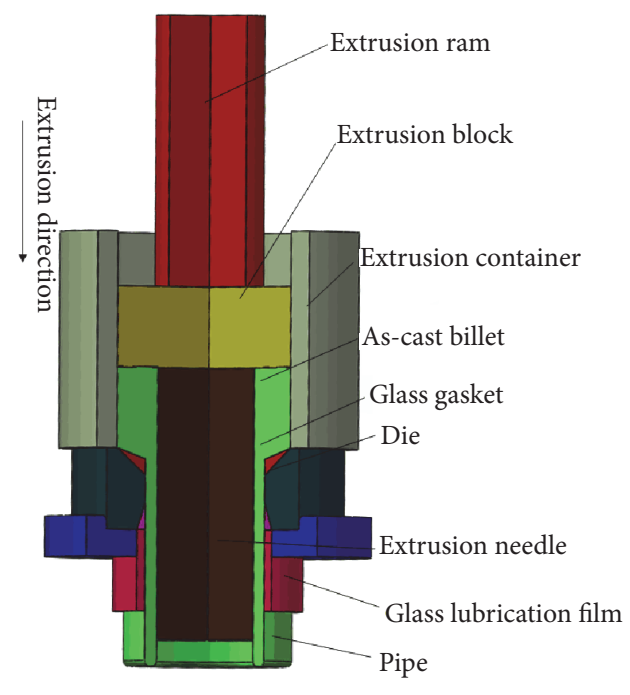

(a)

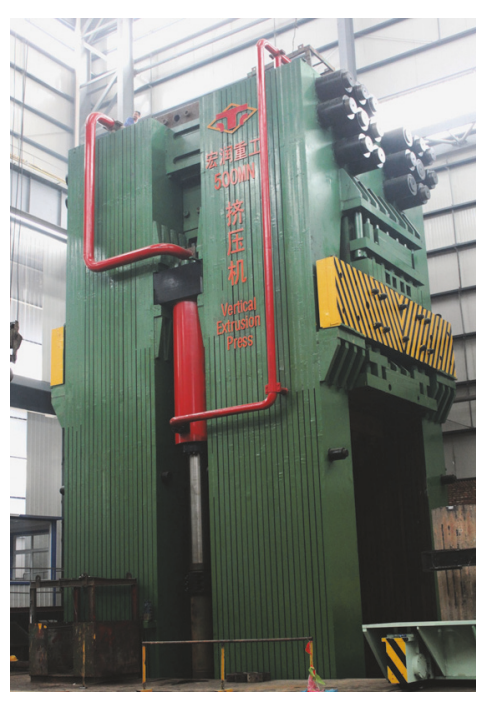

(b)

FIGURE 15: The structural diagram (a); $500 \mathrm{MN}$ vertical hot extrusion machine (b).

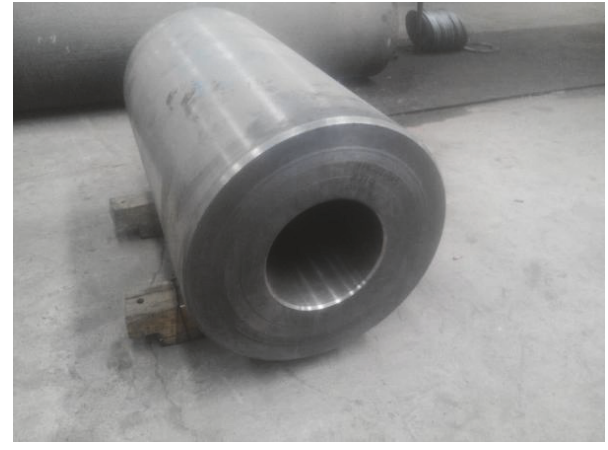

(a)

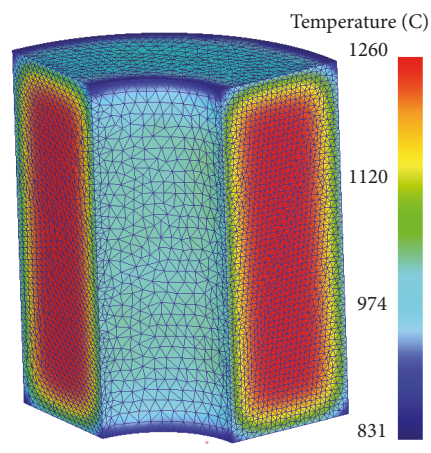

(b)

FigURE 16: Experimental billet (a); billet temperature distribution before extrusion (b).

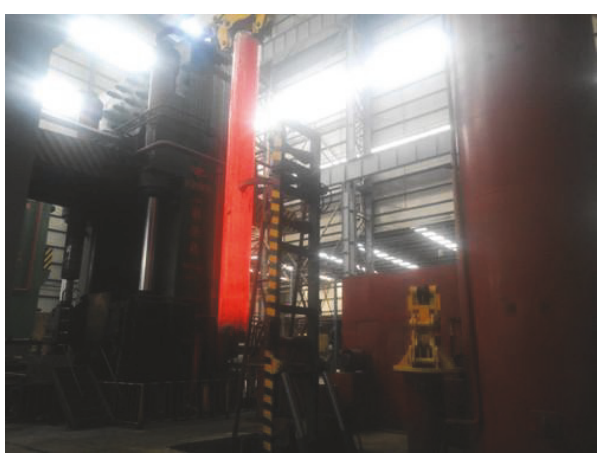

(a)

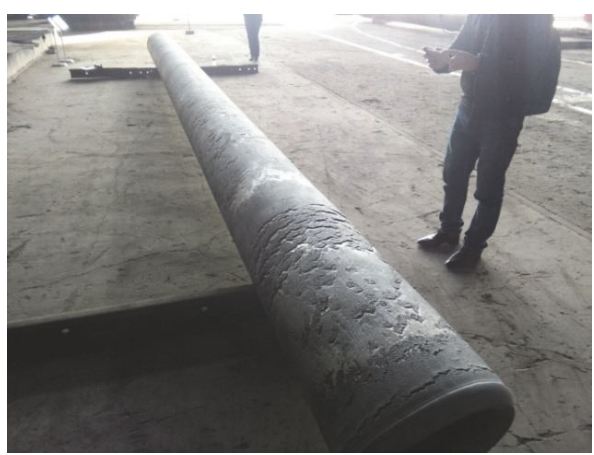

(b)

FIGURE 17: The extruded pipe under the extrusion process (a); after the extrusion (b). 


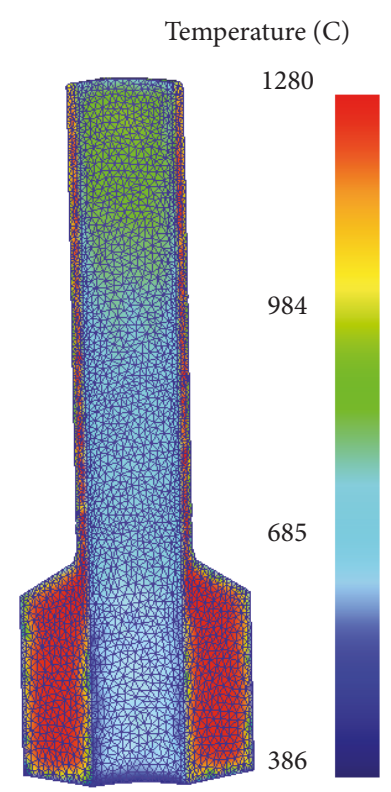

(a)

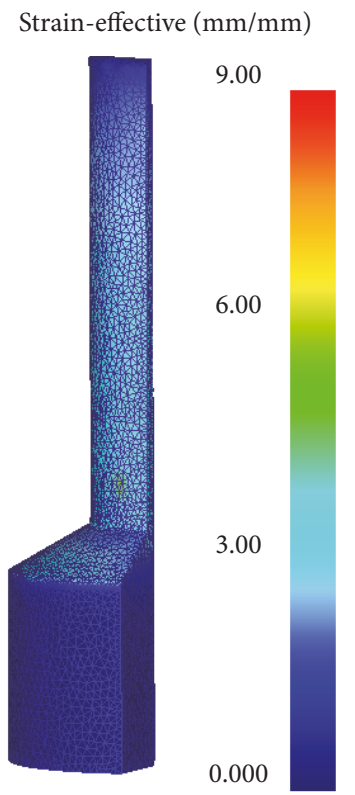

(b)

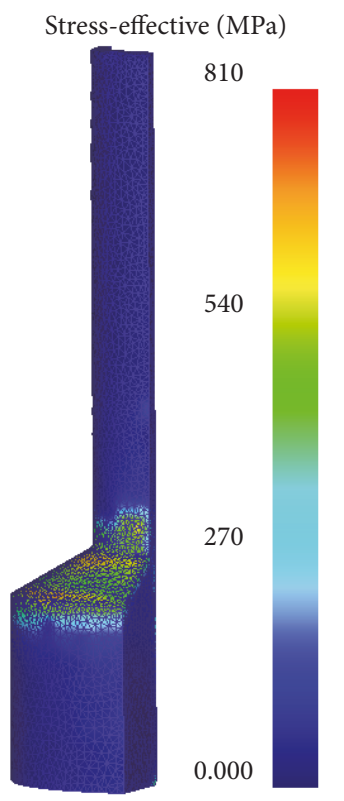

(c)

FIGURE 18: Simulation results of hot extrusion at temperature field (a); effective strain field (b); effective stress field (c).

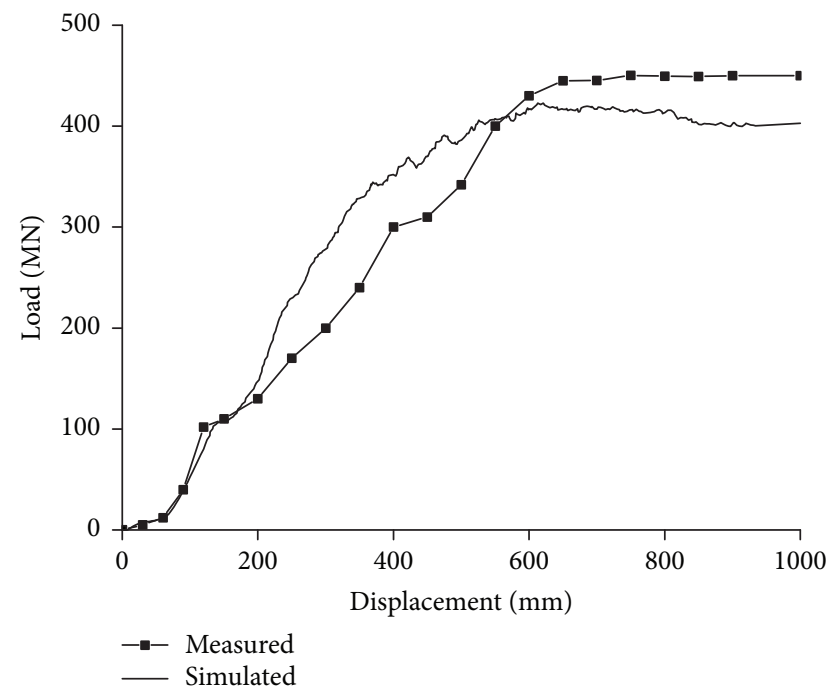

FIGURE 19: The comparisons between measured and simulated displacement-load curves.

\section{Conflicts of Interest}

The authors declare that there are no conflicts of interest regarding the publication of this paper.

\section{Acknowledgments}

The authors would like to express their gratitude to the Research Project Supported by Shanxi Scholarship Council of China (Grant no. 2015-086), the National Natural Science Foundation of China (Grant no. 51675361), and the Fund for Shanxi Key Subjects Construction for funding this work.

\section{References}

[1] Y. T. Li, L. Jia, and J. H. Fu, “Thick-walled seamless steel tube short tube short process casting and squeezing continuous formation method," China Patent, ZL201310025737.4, 2015.

[2] G. G. Shu, Research and application of improved domestic T/P91 steels on the technology and microstructure and mechanical properties [Ph.D. Thesis], Wuhan University, Wuhan, China, 2004.

[3] Z. H. Zou, X. Z. Ou, and L. A. Ni, “Technology and equipment development of hot extrusion forming for steel tubes (Chinese)," Bao Gang Technology, vol. 5, pp. 15-19, 2008 (Chinese).

[4] E. Isaac Samuel and B. K. Choudhary, "Tensile work hardening behaviour of P91 steel," Materials Science and Engineering A, vol. 528, no. 25-26, pp. 7827-7830, 2011.

[5] X. F. Wang, R. D. Wu, and C. X. Deng, "Mechanical properties of new heat-resistant high-tensile steel P91 at high temperature (Chinese)," Chinese Journal of Mechanical Engineering, vol. 44, no. 06, p. 243, 2008 (Chinese).

[6] J. Zhao, D. Li, and Y. Fang, "Statistical analysis and reliability prediction of creep rupture property for T91/P91 steel (Chinese)," Acta Metallurgica Sina, vol. 45, pp. 835-839, 2008 (Chinese).

[7] M. J. Luton and C. M. Sellars, "Dynamic recrystallization in nickel and nickel-iron alloys during high temperature deformation," Acta Metallurgica, vol. 17, no. 8, pp. 1033-1043, 1969.

[8] D. Samantaray, S. Mandal, and A. K. Bhaduri, "A comparative study on Johnson Cook, modified Zerilli-Armstrong and Arrhenius-type constitutive models to predict elevated temperature flow behaviour in modified 9Cr-1Mo steel," Computational Materials Science, vol. 47, no. 2, pp. 568-576, 2009.

[9] Y. C. Lin, Y.-C. Xia, X.-M. Chen, and M.-S. Chen, "Constitutive descriptions for hot compressed 2124-T851 aluminum alloy over a wide range of temperature and strain rate," Computational Materials Science, vol. 50, no. 1, pp. 227-233, 2010. 
[10] H. Mirzadeh, J. M. Cabrera, J. M. Prado, and A. Najafizadeh, "Hot deformation behavior of a medium carbon microalloyed steel," Materials Science and Engineering A, vol. 528, no. 10-11, pp. 3876-3882, 2011.

[11] J. Wang, H. T. Yang, X. G. Wang, and H. Xiao, "A new mathematical model for predicting flow stress up to the critical strain during hot deformation," Materials and Design, vol. 65, pp. 637-643, 2015.

[12] M. Pérez, "Impact of annealing treatments on the softening and work hardening behaviour of Jethete M152 alloy for subsequent cold forming processes," Materials Science and Engineering: A, vol. 690, pp. 303-312, 2017.

[13] J. Feng, H. F. Sun, J. C. Li et al., “Tensile flow and work hardening behaviors of ultrafine-grained Mg-3Al-Zn alloy at elevated temperatures," Materials Science and Engineering A, vol. 667, pp. 97-105, 2016.

[14] Y. Lin, D. Wen, J. Deng, G. Liu, and J. Chen, "Constitutive models for high-temperature flow behaviors of a Ni-based superalloy," Materials \& Design, vol. 59, pp. 115-123, 2014.

[15] Y. W. Zhai, A study on grain evolution characteristics of P91 steel and numerical simulation of hot extrusion of thick wall tube [Ph.D. thesis], China Academy of Machinery Science and Technology, Beijing, China, 2013.

[16] S.-I. Kim, Y. Lee, D.-L. Lee, and Y.-C. Yoo, "Modeling of AGS and recrystallized fraction of microalloyed medium carbon steel during hot deformation," Materials Science and Engineering A, vol. 355, no. 1-2, pp. 384-393, 2003.

[17] S.-I. Kim and Y.-C. Yoo, "Dynamic recrystallization behavior of AISI 304 stainless steel," Materials Science and Engineering A, vol. 311, no. 1-2, pp. 108-113, 2001.

[18] Y. Lee, B. M. Kim, K. J. Park, S. W. Seo, and O. Min, "A study for the constitutive equation of carbon steel subjected to large strains, high temperatures and high strain rates," Journal of Materials Processing Technology, vol. 130-131, pp. 181-188, 2002.

[19] R. Bhattacharya, Y. J. Lan, B. P. Wynne, B. Davis, and W. M. Rainforth, "Constitutive equations of flow stress of magnesium AZ31 under dynamically recrystallizing conditions," Journal of Materials Processing Technology, vol. 214, no. 7, pp. 1408-1417, 2014.

[20] N. Kim and H. Choi, "The prediction of deformation behavior and interfacial friction under hot working conditions using inverse analysis," Journal of Materials Processing Technology, vol. 208, no. 1-3, pp. 211-221, 2008.

[21] F. Gao, F.-X. Yu, F.-T. Liu, and Z.-Y. Liu, "Hot deformation behavior and flow stress prediction of ultra purified $17 \% \mathrm{Cr}$ ferritc stainless steel stabilized with $\mathrm{Nb}$ and Ti," Journal of Iron and Steel Research International, vol. 22, no. 9, Article ID 30077, pp. 827-836, 2015. 

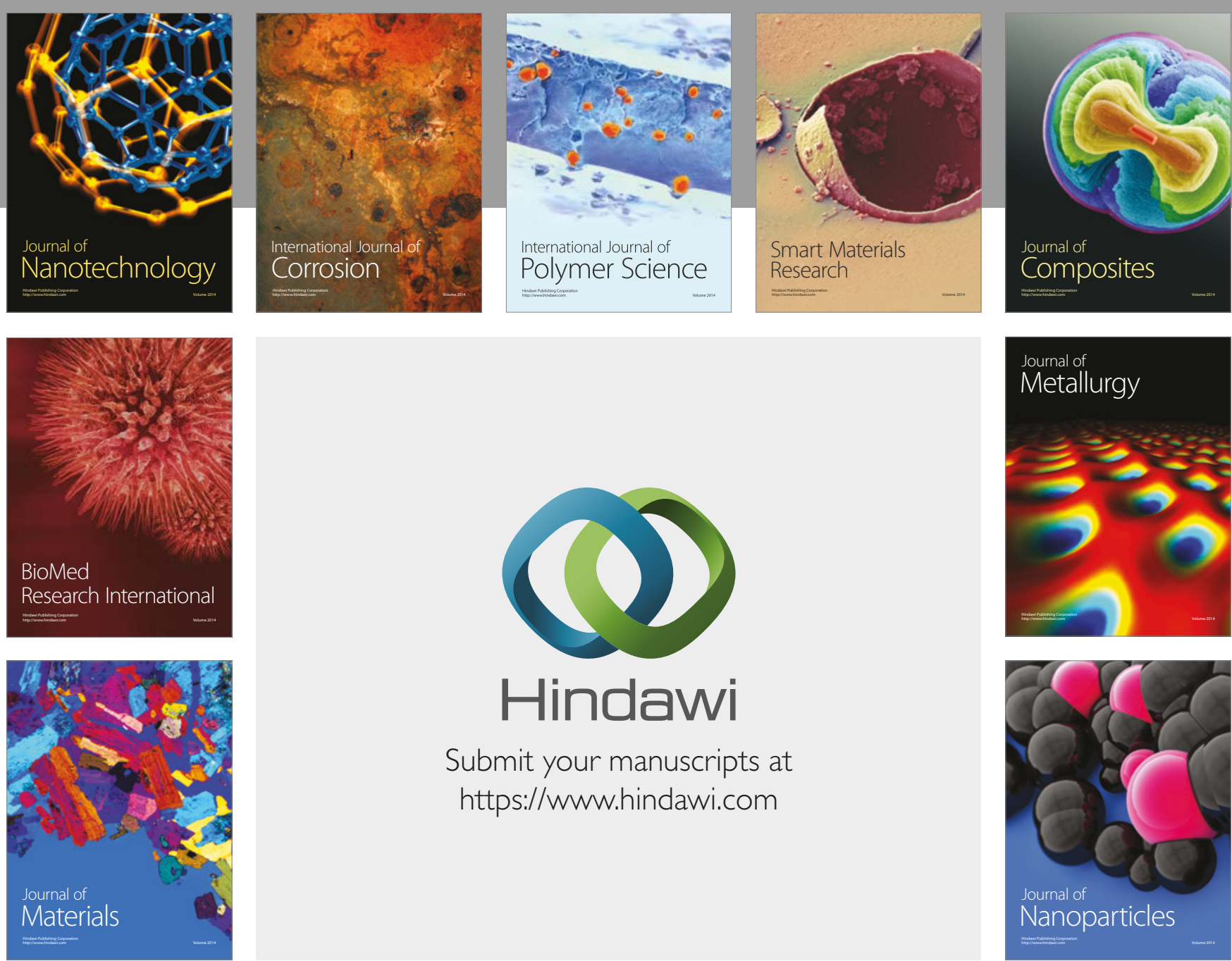

\section{Hindawi}

Submit your manuscripts at

https://www.hindawi.com
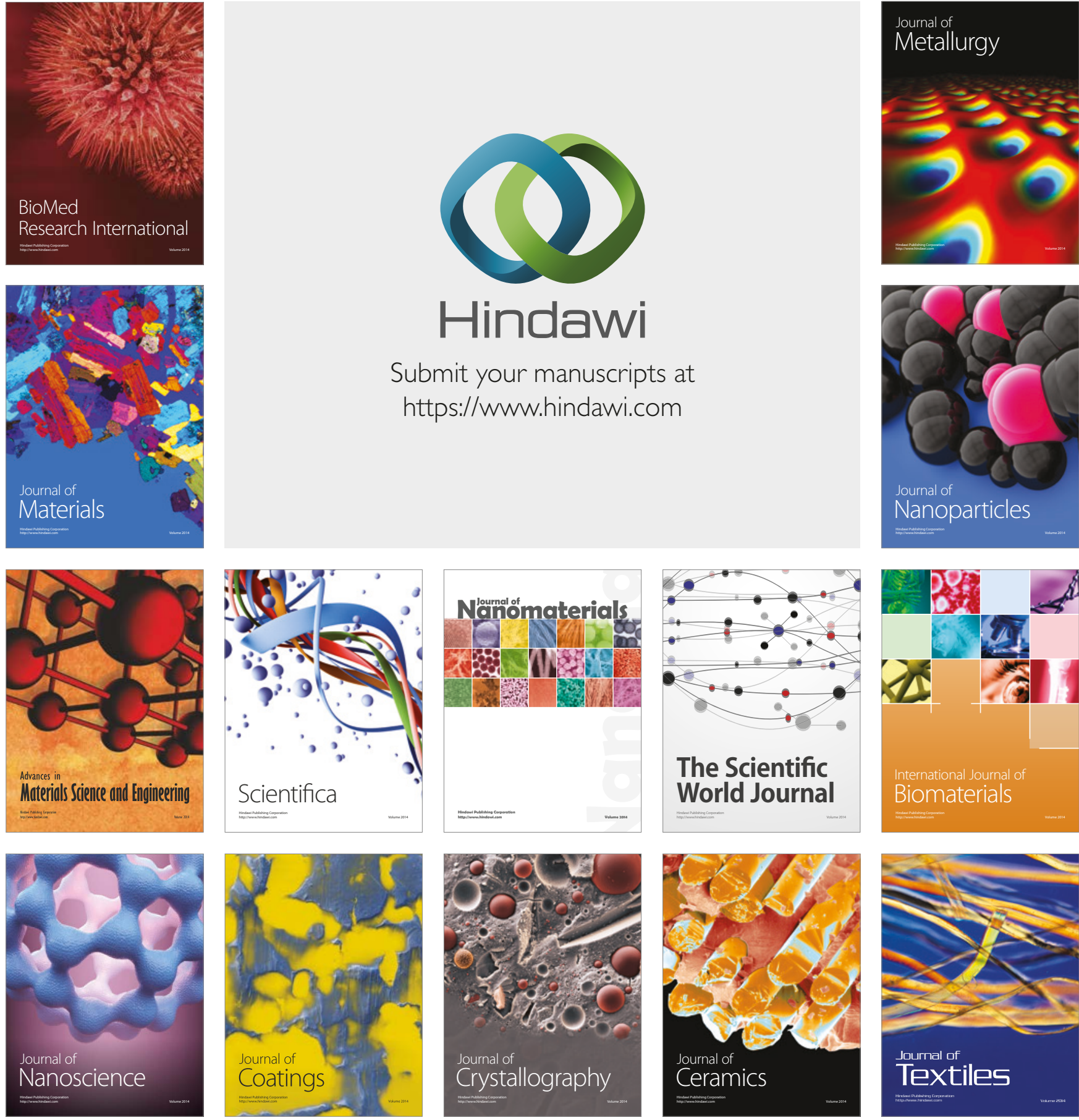

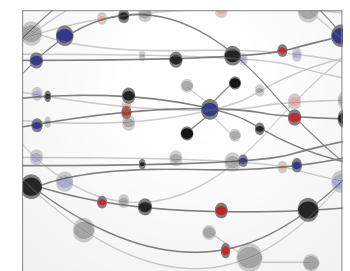

The Scientific World Journal
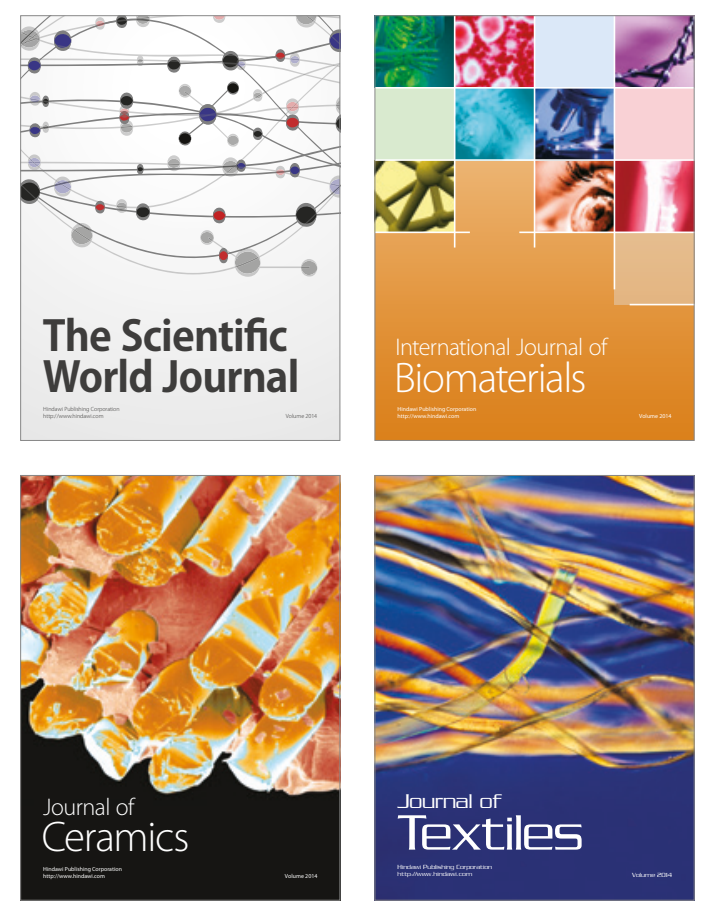